\title{
Monozygotic twins with chromosome 22q11 deletion and discordant phenotype
}

\author{
J Goodship, I Cross, P Scambler, J Burn
}

\begin{abstract}
We report monozygotic twins concordant for $22 \mathrm{q} 11.2$ deletion but discordant for clinical phenotype. Both boys show the typical dysmorphic features with short palpebral fissures, square nasal tip, small mouth, and both have nasal speech, but only one twin had a heart defect. They show that the phenotypic variability seen in this microdeletion syndrome cannot be explained on the basis of genotypic differences alone.
\end{abstract}

(F Med Genet 1995;32:746-748)

Chromosome 22q11 deletions cause a spectrum of clinical problems ranging from isolated congenital heart disease through velocardiofacial syndrome to DiGeorge syndrome (DGS). ${ }^{1-9}$ The acronym CATCH 22 (Cardiac abnormality, Abnormal face, $\mathrm{T}$ cell deficit, Cleft palate, and Hypocalcaemia owing to chromosome 22 deletion) has been used to encompass the overlapping phenotypes. ${ }^{10}$ Studies into genotype-phenotype correlation have made little headway as all the deletions identified have been greater than 2 megabases whatever the phenotype. ${ }^{11-13}$ Indeed the phenotype is so variable in families that we have identified family members who have the deletion but have never presented with a clinical problem. Possible explanations for this include changes in the size of the deletion within families, other modifying genetic loci, environmental factors, or chance events. A better understanding of the factors accounting for the phenotypic variability would be of great help in the counselling situation. The monozygous twin pair we describe is important because clearly differences in deletion size and modifying genetic loci are not responsible for their phenotypic differences.

Department of Genetics, University of Newcastle upon Tyne, 19/20 Claremont Place, Newcastle upon Tyne NE2 4AA, UK

J Goodship

I Cross

J Burn

Institute of Child Health, London WC1N 1EH, UK

P Scambler

Correspondence to: Dr Goodship.

Received 29 November 1994 Revised version accepted for publication 11 May 1995

\section{Case report}

The twins were delivered by caesarean section at 38 weeks' gestation to unrelated parents of white European origin. The mother was 32 and the father was 29 and this was the first pregnancy. Both parents were clinically normal and there was no family history of congenital heart disease or other handicap. The twins were said to have a single placenta though detailed examination findings were not recorded. Twin 1 weighed $2200 \mathrm{~g}$ and twin 2 weighed $2800 \mathrm{~g}$.
A heart murmur was noted in twin 1 at 1 week and tetralogy of Fallot was diagnosed at 8 weeks of age. At 1 year of age he underwent transatrial repair of the Fallot's tetralogy with resection of fibromuscular infundibular muscle, Dacron patch closure of the VSD, and resection of fibrous membrane from the left ventricular outflow tract. His initial recovery was complicated by supraventricular dysrhythmias and left ventricular dysfunction. Pre- and postoperative calcium levels were normal. Twin 2 has a normal cardiovascular system on clinical examination and a normal echocardiogram.

At 24 months of age twin 1 is just starting to take steps while his brother stood at 13 months and walked steadily by 18 months. At 24 months they have a vocabulary of about 40 words and will join two words together, though twin 2's vocabulary is more extensive. Both twins are able to point to body parts, build towers, and imitate household jobs.

The parents had noted that twin 1 had nasal regurgitation of feeds as a baby and both twins now have nasal speech.

Both twins have a small mouth, square nasal tip, short palpebral fissures, and small ears with deficient upper helices (figure). Twin 1 has bilateral hair whorls and twin 2 has a right sided hair whorl. Toes 4 and 5 are curled under bilaterally in both boys, this being more marked in twin 1 .

CYTOGENETIC ANALYSIS

High resolution cytogenetic analysis showed $46, \mathrm{XY}, \operatorname{del}(22)(\mathrm{q} 11.21 \mathrm{q} 11.23)$ in each twin. This deletion was confirmed by fluorescent in situ hybridisation using the cosmids CO568, which detects the same loci as SC11.1,11 and C179. ${ }^{13}$ CO568 detects two loci 2 megabases apart which flank the DGS critical region and C179 lies within the DGS critical region. One hundred metaphases were counted from each twin and all showed the deletion. On FISH studies neither parent had the deletion.

\section{Zygosity studies} samples was carried out by standard methods. HinfI filters were probed with four hypervariable DNA polymorphisms, MS43 $\alpha$, G3, YNH24, and MS $1 .{ }^{14}$ Each probe detected four alleles in the parents and for each the genotype in the twins was identical. In addition the twins
Southern blot analysis of the parental and twin 


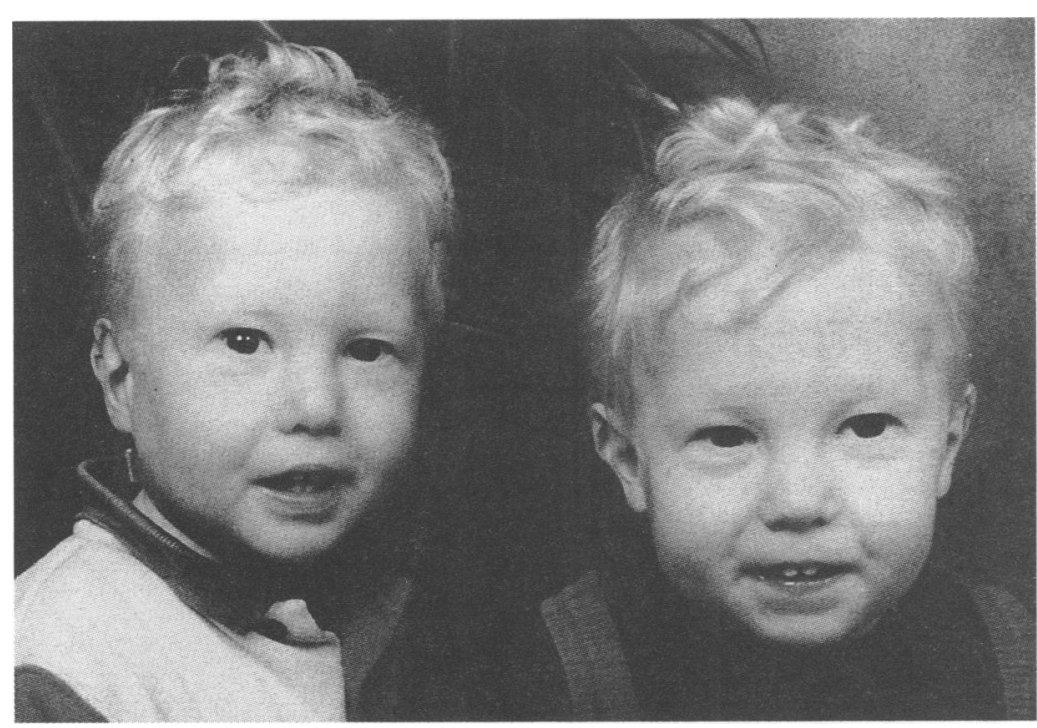

Photograph of the twins with twin 1 on the left and twin 2 on the right.

were identical when typed for the following red cell antigens: ABO, rhesus, MNSs, Colton, Kell, Lutheran, Duffy, Kidd, and Xg. Analysis of the DNA and red cell antigen information using Bayes's theorem gives a probability of dizygosity of 0.000156 .

\section{Discussion}

There is no doubt that these twins are monozygotic. Monozygotic twins are genetically identical unless somatic mutations have occurred. While the deletion breakpoints in these twins have not been cloned and formally shown to be the same the fact that the deletion is detected by $\mathrm{CO} 568$ shows that the deletion in both is in the order of 2 megabases and is larger than the DGS critical region. Thus genotypic differences are unlikely to be the explanation for their phenotypic differences.

A possible explanation for the difference in phenotype would be if the twins were mosaic for the cytogenetic abnormality and the proportion of abnormal cells was higher in twin 1 . Examination of 100 metaphases from each twin showed deletion in all cells. In addition the fact that the facial features are so similar in the twins shows that all tissues contributing to facial appearance are involved. In short it is extremely unlikely that the cause of the discordance is mosaicism.

Although both twins have the facial features of DGS only twin 1 has a cardiac defect. Twin 1 was smaller than twin 2 and in all areas his development has been a little slower than that of his brother. It is difficult to know how much of this can be accounted for by his numerous hospital admissions. The parents report that there was also a slowing of development in twin 2 around the age of 1 year when his twin had a number of hospital admissions. The nasal speech is more obvious in twin 1 and the toe deformity is more marked in twin 1 .

Heart malformations are more common in
$\mathrm{MZ}$ twins and usually affect only one of the pair. ${ }^{15-17}$ Thus it could be argued that the heart defect in twin 1 resulted from the twinning process rather than the chromosome deletion. However, the incidence of tetralogy of Fallot is much higher in children with chromosome $22 \mathrm{q} 11$ deletions than it is in $M Z$ twins.

The heart defect in twin 1 is almost certainly the result of the chromosomal abnormality. The fact that only one of the twins has a cardiac defect indicates that either chance or other nongenetic factors influence cardiac development when there is such a deletion. It is interesting that the twin with tetralogy of Fallot was the smaller twin. The twinning process imposes a growth disadvantage which, depending on the blood flow to each twin, may be more severe in one than the other. This is one of the mechanisms which may account for discordance of malformations in twin pairs. Other influences of the twinning process which may cause discordant cardiovascular anomalies include disturbance of laterality and placental vascular anastomoses leading to twin-twin transfusion. Whichever mechanism is invoked, the most plausible hypothesis is that $22 \mathrm{q} 11$ deletion predisposed this monozygotic twin pair to heart malformation and the additive effect of the twinning process caused one of the pair to manifest a heart defect.

The fact that the genotype does not account for all the phenotypic differences in this family implies that we are unlikely to find genetic explanations for all of the phenotypic variation seen within dominant families. This being the case, counselling such families, particularly about prenatal tests, will continue to be difficult as the phenotype cannot be accurately predicted from the genotype.

We wish to thank the parents for their help in compiling this report and $\mathrm{Mr}$ W Brawn, who carried out the cardiac surgery at Birmingham Children's Hospital, Dr J Wright, and Dr E
Ladusans for their helpful comments. Mr K Creen and Ms S Stenhouse performed the zygosity testing.

1 Driscoll DA, Spinner NB, Budarf ML, et al. Deletions and microdeletions of 22q11.2 in velo-cardio-facial syndrome. Am f Med Genet 1992;44:261-8.

2 Driscoll DA, Salvin J, Sellinger B, et al. Prevalence of 22q11 microdeletions in DiGeorge and velocardiofacial syndromes: implications for genetic counselling and presyndromes: implications for genetic counsellin

3 Goldmuntz E, Driscoll D, Budarf ML, et al. Microdeletions of chromosome 22q11 in patients with congenital conotruncal cardiac defects. $\mathcal{F}$ Med Genet 1993;30:807-12.

4 Wilson DI, Goodship JA, Burn J, Cross IE, Scambler PJ. Deletions within chromosome 22q11 in familial congenital heart disease. Lancet 1992;340:573-5.

5 Scambler PJ, Kelly D, Lindsay E, et al. Velo-cardio-facial syndrome associated with chromosome 22 deletions encompassing the DiGeorge locus. Lancet 1992;339:1138-9.

6 Carey AH, Kelly D, Halford S, et al. Molecular genetic study of the frequency of monosomy $22 \mathrm{q} 11$ in DiGeorge syndrome. Am ₹ Hum Genet 1992;51:964-70.

7 Scire G, Dallapiccola B, Iannetti P, et al. Hypoparathyroidism as the major manifestation in two patients with 22q11 deletions. Am $\mathcal{F}$ Med Genet 1994;52:478-82.

8 Lipson A, Emanuel BS, Colley P, Fagan K, Driscoll DA. "CATCH 22" sans cardiac anomaly, thymic hypoplasia, cleft palate, and hypocalcaemia: cAtch 22. A common

9 Matsuoka R, Takao A, Kimura M, et al. Confirmation that Matsuoka R, Takao A, Kimura M, et al. Confirmation that
the conotruncal anomaly face syndrome is associated with the conotruncal anomaly face syndrome is associated with 285-9.

10 Wilson DI, Burn J, Scambler P, Goodship J. Di George syndrome: part of CATCH 22. F Med Genet 1993;30: 852-6.

11 Halford S, Lindsay E, Nayudu M, et al. Low-copy-number repeat sequences flank the DiGeoge/velocardiofacial syndrome loci at 22q11. Hum Mol Genet 1993;2:191-6. 
12 Desmaze C, Scambler P, Prieur M, et al. Routine diagnosis of DiGeorge syndrome by fluorescent in situ hybridisation. Hum Genet 1993;90:663-5.

13 Halford S, Wadey R, Roberts C, et al. Isolation of a putative transcriptional regulator from the region of $22 \mathrm{q} 11$ deleted and familial congenital heart disease. Hum Mol Genet 1993;2:2099107 .

14 Wong Z, Wilson V, Patel I, Povey S, Jeffreys A. Characterisation of a panel of highly variable minisatellites cloned from human DNA. Ann Hum Genet 1987;51: 269-88.

15 Bum J. Monozygotic twins. In: Chamberlain G, ed. Contemporary obstetrics and gynaecology. London: Butterworths, temporary obstetri

16 Burn J, Corney G. Congenital heart defects and twinning. Acta Genet Med Gemellol 1984;33:61-9.

17 Burn J. The aetiology of congenital malformation: an analysis of genetic contribution. MD Thesis, University of Newcastle upon Tyne, 1991. 